\title{
Rates of emergency department visits attributable to alcohol use in Ontario from 2003 to 2016: a retrospective population-level study
}

\author{
Daniel T. Myran MD MPH, Amy T. Hsu PhD, Glenys Smith MSc, Peter Tanuseputro MD MHSc
}

Cite as: CMAJ 2019 July 22;191:E804-10. doi: 10.1503/cmaj.181575

Visual abstract available at www.cmaj.ca/lookup/suppl/doi:10.1503/cmaj.181575/-/DC2

See related article at www.cmaj.ca/lookup/doi/10.1503/cmaj.190818

\begin{abstract}
BACKGROUND: Alcohol use causes a large burden on the health of Canadians, and alcohol-related harms appear to be increasing in many high-income countries. We sought to analyze changes in emergency department visits attributable to alcohol use, by sex, age and neighbourhood income over time.
\end{abstract}

METHODS: All individuals aged 10 to 105 years living in Ontario, Canada, between 2003 and 2016 were included in this study. The primary outcome was age-standardized rates of emergency department visits attributable to alcohol use, defined using diagnostic codes from the Canadian Institute for Health Information Health Indicator "hospitalizations entirely caused by alcohol." We compared rates of these visits using a retrospective populationlevel design.

RESULTS: Among 15121639 individuals, there were 765346 emergency department visits attributable to alcohol use over the study period. Between 2003 and 2016, the age-standardized rates of these visits increased more in women $(86.5 \%)$ than in men $(53.2 \%)$, and the increase in rates of emergency department visits attributable to alcohol use was 4.4 times greater than the increases in the rates of overall emergency department visits. Individuals aged 25-29 years experienced the largest change in the rate of emergency department visits attributable to alcohol use (175\%). We found evidence of age-cohort effects, whereby the rate of emergency department visits attributable to alcohol use at age 19 years increased on average by $4.07 \%(95 \%$ confidence interval $[\mathrm{Cl}]$ $3.71 \%-4.44 \%$ ) per year for each cohort born between 1986 and 1999. Individuals in the lowest neighbourhood income quintile had $2.37(95 \% \mathrm{Cl} 2.27-$ 2.49) times the rate of emergency department visits attributable to alcohol use than those in the highest income quintile. This disparity increased slightly over the study period.

INTERPRETATION: Although men and lower-income individuals have the highest burden of emergency department visits attributable to alcohol use, the largest increases in visits have been in women and younger adults. Further research should focus on potential causes of these trends to provide guidance on how to reduce alcohol-related harms.
I

n Canada, alcohol use led to an estimated $5.8 \%$ of deaths in men and $0.6 \%$ of deaths in women in $2017 .{ }^{1}$ Alcohol use also imposes a substantial burden on the Canadian health system; between 2014 and 2015, there were 77000 hospital admissions entirely attributable to alcohol, exceeding the number of admissions for coronary artery disease. ${ }^{2}$ A growing body of evidence from the United States, England and Australia has found that alcohol-related mortality and harms, such as hospital admissions or emergency department visits attributable to alcohol use, have increased over the past 2 decades..$^{3-5}$ In 2015, rates of hospital admissions attributable to alcohol in Canada were higher in men than in women and older adults. ${ }^{2}$ Furthermore, mortality rates specifically attributable to alcohol-related liver disease have been increasing over time in Canada. ${ }^{1}$ However, data are lacking on how population-level emergency department visits or hospital admissions attributable to alcohol use in Canada have changed over time and, importantly, whether any changes differ by factors such as age, sex and socioeconomic status.

Although alcohol harms appear to be increasing in highincome countries, to our knowledge, only one study set in England has examined contemporary population-level changes in alcohol-related harms by age, sex and income. ${ }^{4}$ Emerging data 
from the US examining the phenomenon known as the "deaths of despair" (i.e., death by drug poisoning, suicide and alcoholic liver disease) have shown widening socioeconomic gradients, with disproportionate increases in these deaths among white non-Hispanic individuals with lower income and educational attainment. ${ }^{6}$ Although Canadian data have also shown disparities in alcohol-related harms between low- and high-income groups, ${ }^{7}$ data are lacking on changes in this relation over time.

There are important differences between Canada and the US, including less pronounced income inequality, different population demographics, distinctive patterns of alcohol consumption by socioeconomic groups and, in general, more stringent controls on alcohol in Canada. ${ }^{8}$ Consequently, although US-based studies are informative, a better understanding of Canadianspecific trends contributing to alcohol-related harms is pertinent to identifying high-risk populations, and for guiding public health policy and patient care.

To address these gaps, we examined temporal patterns of change in emergency department visits attributable to alcohol use, by sex, age and neighbourhood income, between 2003 and 2016 in Ontario, the largest province in Canada.

\section{Methods}

\section{Study design and population}

We conducted a retrospective population-level study in Ontario, Canada, using administrative data collected from the province's universal health care system. We included all individuals over the age of 10 years - for whom harmful alcohol use could be considered as intentional - between Jan. 1, 2003, and Dec. 31, 2016. We excluded individuals not eligible for the provincial health insurance program and those older than 105 years.

\section{Data sources}

Data sets used in this study included the National Ambulatory Care Reporting System database, which contains visit records from emergency departments; the Registered Persons Database, a registry of all individuals eligible for the provincial health insurance plan containing individual demographic information such as age, sex and postal code of primary residence; and the 2011 Postal Code Conversion File Plus, which contained information on individuals' neighbourhood income quintile and the rurality of their home address. These data sets were linked using unique, encoded identifiers assigned to each person and analyzed at ICES. The population-level database used in this study has been estimated to capture $100 \%$ of emergency department visits in Ontario. ${ }^{9}$

\section{Outcomes}

The primary outcome was an emergency department visit attributable to alcohol use, defined using a set of diagnostic codes from the International Classification of Diseases, 10th Revision (ICD-10) contained in the Canadian Institute for Health Information Health Indicator "hospitalizations entirely caused by alcohol." Emergency department visits were considered to be attributable to alcohol use when a code from the indicator was listed as the main reason for the visit or having contributed to the visit (see Appendix 1, Supplementary Table 1, available at www.cmaj. ca/lookup/suppl/doi:10.1503/cmaj.181575/-/DC1, for the complete list of codes). In addition, we examined changes in emergency department visits, attributable to any cause, in Ontario over the same period.

\section{Statistical analysis}

We calculated frequencies, proportions and standardized differences to characterize and compare the study population across age groups, sex and neighbourhood income quintiles. Rates were directly standardized by age (when appropriate) using the 2011 Census population as the reference (the most recent available reference year at the time of analysis). As the study was conducted at the population level (using a census of the population instead of randomly selected samples from within a population), inferential statistical analyses were not performed to compare absolute changes between 2003 and 2016. ${ }^{10}$ We calculated risk ratios (RRs) to compare rates of emergency department visits in low-income and high-income neighbourhoods, and the average annual percent change to compare rates of visits across birth cohorts. We then conducted time-trend analyses on changes in the ratio between high- and low-income neighbourhoods and between rates of visits in different birth cohorts using Poisson models with year as a continuous predictor and population size as an offset. All analyses were performed using SAS software version 9.4.3.

\section{Ethics approval}

ICES is a prescribed entity under section 45 of Ontario's Personal Health Information Protection Act. Section 45 authorizes ICES to collect personal health information, without consent, for the purpose of analysis or compiling statistical information with respect to the management of, evaluation or monitoring of, allocation of resources to or planning for all or part of the health system. This project was conducted under section 45, and approved by the ICES Privacy and Compliance Office.

\section{Results}

\section{Burden of emergency department visits attributable to alcohol use}

Our cohort included 15121639 individuals who were followed for an average of 11.05 (4.28) person-years for a total of 167228195 person-years. There were 765346 emergency department visits (32.3\% female patients) attributable to alcohol use incurred by 480611 Ontario residents aged between 10 and 105 years over the 14 -year study period. This represented $1.18 \%$ of the total number of emergency department visits in Ontario. Women who experienced an emergency department visit attributable to alcohol use were more likely than men to be below the legal drinking age of 19 years (17.4\% women, 9.1\% men). Women were less likely to be in the lowest income quintile and to have visited the emergency department more than once because of alcohol use in the past year (Table 1). Emergency department visits attributable to alcohol use resulted in a higher rate of subsequent 
Table 1: Characteristics of Ontario residents who visited the emergency department because of alcohol use, 2003-2016 $(n=480611)$

\begin{tabular}{|c|c|c|c|}
\hline \multirow[b]{2}{*}{ Characteristic } & \multicolumn{2}{|c|}{ No. $(\%)$ of patients* } & \multirow[b]{2}{*}{$\begin{array}{c}\text { Standardized } \\
\text { difference }\end{array}$} \\
\hline & $\begin{array}{c}\text { Women } \\
n=170225\end{array}$ & $\begin{array}{c}\text { Men } \\
n=310386\end{array}$ & \\
\hline $\begin{array}{l}\text { No. of visits attributable to alcohol use (\% of total visits), } \\
n=765346\end{array}$ & $247044(32.3)$ & $518302(67.7)$ & - \\
\hline No. of visits in year of initial visit, mean \pm SD & $1.45 \pm 2.05$ & $1.67 \pm 3.32$ & 0.80 \\
\hline 1 visit & $141481(83.1)$ & $246752(79.5)$ & 0.09 \\
\hline 2 visits & $15971(9.4)$ & $32940(10.6)$ & 0.04 \\
\hline 3 visits & $5234(3.1)$ & $11681(3.8)$ & 0.04 \\
\hline 4 visits & $2425(1.4)$ & $5711(1.8)$ & 0.03 \\
\hline$\geq 5$ visits & $5114(3.0)$ & $13302(4.3)$ & 0.07 \\
\hline \multicolumn{4}{|l|}{ Age, yrt } \\
\hline Age, mean \pm SD & $36.42 \pm 17.79$ & $41.09 \pm 17.31$ & 0.27 \\
\hline $10-18$ & $29646(17.4)$ & $28315(9.1)$ & 0.25 \\
\hline $19-24$ & $33312(19.6)$ & $47220(15.2)$ & 0.12 \\
\hline $25-40$ & $38398(22.6)$ & $74084(23.9)$ & 0.03 \\
\hline $41-64$ & 56003 (32.9) & $130635(42.1)$ & 0.19 \\
\hline $65-80$ & $10799(6.3)$ & $26811(8.6)$ & 0.09 \\
\hline$>80$ & $2067(1.2)$ & $3321(1.1)$ & 0.01 \\
\hline \multicolumn{4}{|l|}{ Income quintile } \\
\hline 1 (lowest) & $48754(28.6)$ & $95616(30.8)$ & 0.05 \\
\hline 2 & 33115 (19.5) & $63896(20.6)$ & 0.03 \\
\hline 3 & $29115(17.1)$ & $54271(17.5)$ & 0.01 \\
\hline 4 & $28130(16.5)$ & $47917(15.4)$ & 0.03 \\
\hline 5 (highest) & $28867(17.0)$ & $43932(14.2)$ & 0.08 \\
\hline \multicolumn{4}{|l|}{ Population centre and rural area classification } \\
\hline Large urban population centre $(\geq 100000)$ & $110660(65.0)$ & $207245(66.8)$ & 0.01 \\
\hline Medium population centre (30 000-99 999) & $16170(9.5)$ & $27476(8.9)$ & 0.02 \\
\hline Small population centre (1000-29 999) & $18600(10.9)$ & $31815(10.3)$ & 0.04 \\
\hline Rural population centre $(<1000)$ & $24731(14.5)$ & $43797(14.1)$ & 0.01 \\
\hline
\end{tabular}

admission to hospital (13.1\%) than general emergency department visits (9.6\%).

The most common diagnostic codes for emergency department visits attributable to alcohol use were for intoxication (44.6\%), harmful use (21.4\%), withdrawal (11.4\%) and alcohol dependence (10.9\%). The most common medical harms were alcoholic liver disease (2.8\%), alcoholic gastritis (1.5\%) and alcohol poisoning (2.6\%) (Table 2). A full list of individual diagnostic codes stratified by sex is available in Appendix 1, Supplementary Table 1 . The average annual percentage change in the crude and age- and sex-adjusted rates of codes per 10000 individuals are available in Appendix 1, Supplementary Table 2. In 2003, alcoholrelated ICD codes were listed as the main reason for visiting the emergency department for $66.7 \%$ of visits and as a contributing reason in $33.3 \%$ of visits. In 2016, $71.7 \%$ of codes were listed as the main reason for visiting the emergency department.

\section{Temporal trends in emergency department visits attributable to alcohol use}

The total number of emergency department visits attributable to alcohol, the number of individuals visiting the emergency department because of alcohol use, and the average number of emergency department visits attributable to alcohol use per individual increased between 2003 and 2016 (Table 3). With stratification by sex, the absolute increase in age-standardized incidence of emergency department visits attributable to alcohol between 2003 and 2016 was greater in men (27.19 per 10000 individuals v. 17.91 per 10000 individuals). However, the relative 
Table 2: Changes in number of visits to the emergency department attributable to alcohol use by diagnostic codes, 2003-2016

\begin{tabular}{|c|c|c|c|c|}
\hline \multirow[b]{2}{*}{ ICD-10 code* } & \multicolumn{3}{|c|}{ No. of visits } & \multirow{2}{*}{$\begin{array}{c}\text { Absolute } \% \\
\text { increase }\end{array}$} \\
\hline & All years & 2003 & 2016 & \\
\hline \multicolumn{5}{|l|}{ Mental health harms } \\
\hline Acute intoxication (F100) & 363566 & 18341 & 34276 & 86.9 \\
\hline Harmful use (F101) & 174942 & 9376 & 17979 & 91.8 \\
\hline Alcohol dependence (F102) & 89118 & 6496 & 6737 & 3.7 \\
\hline Alcohol withdrawal (F103, F104) & 93332 & 4282 & 11010 & 178.2 \\
\hline $\begin{array}{l}\text { Mental and behavioural disorders due to use of alcohol, other, i.e., } \\
\text { psychosis, amnesic syndrome (F105-F109) }\end{array}$ & 8846 & 380 & 1313 & 245.5 \\
\hline \multicolumn{5}{|l|}{ Medical harms } \\
\hline Alcoholic liver disease (K700-K704, K709) & 23192 & 1063 & 2,452 & 130.7 \\
\hline Alcoholic gastritis (K292) & 11799 & 771 & 976 & 26.6 \\
\hline Accidental or intentional poisoning by alcohol $(\mathrm{X} 45, \mathrm{Y} 15, \mathrm{X} 65)$ & 21532 & 1187 & 1898 & 59.9 \\
\hline $\begin{array}{l}\text { Other medical conditions due to alcohol, i.e., alcohol induced: acute } \\
\text { pancreatitis, neuropathy, cardiomyopathy (G312, G621, G721, 1426, K852, } \\
\text { K860, E244, T510, T519, R780) }\end{array}$ & 28618 & 1753 & 2775 & 58.3 \\
\hline $\begin{array}{l}\text { Maternal care for (suspected) damage to fetus from alcohol/Fetal alcohol } \\
\text { syndrome (Q99304, Q99305, Q860, P043) }\end{array}$ & 878 & 6 & 134 & 2133.3 \\
\hline Total & $815823 \ddagger$ & 43655 & 79550 & 82.2 \\
\hline \multicolumn{5}{|c|}{$\begin{array}{l}\text { Note: ICD-10 = International Classification of Diseases, } 10 \text { th Revision. } \\
\text { *See Appendix 1, Supplementary Table } 1 \text { (available at www.cmaj.ca/lookup/suppl/doi:10.1503/cmaj.181575///DC1) for the full description of the ICD-10 codes in the indicator. } \\
\text { †See Appendix } 1 \text {, Supplementary Table } 2 \text { for an analysis of the annual percentage increase in rates of ICD-10 codes accounting for changes in population demographics. } \\
\text { fTotal number of codes exceeds the total number of emergency department visits because some visits were considered to be caused by more than } 1 \text { alcohol-related harm and } \\
\text { therefore were assigned more than } 1 \text { ICD-10 code. }\end{array}$} \\
\hline
\end{tabular}

Table 3: Temporal trends in emergency department visits attributable to alcohol use and all-cause emergency department visits, 2003-2016

\begin{tabular}{|c|c|c|c|c|c|c|}
\hline \multirow[b]{2}{*}{ Characteristic } & \multicolumn{3}{|c|}{ Women } & \multicolumn{3}{|c|}{ Men } \\
\hline & 2003 & 2016 & $\begin{array}{l}\text { Absolute \% } \\
\text { increase }\end{array}$ & 2003 & 2016 & $\begin{array}{l}\text { Absolute } \% \\
\text { increase }\end{array}$ \\
\hline No. of all-cause visits & 2010480 & 2836984 & $41.1^{\star}$ & 1878141 & 2430534 & $29.4^{\star}$ \\
\hline No. of visits attributable to alcohol & 11868 & 24951 & $110.2^{\star}$ & 27962 & 49669 & $77.6^{\star}$ \\
\hline $\begin{array}{l}\text { No. of individuals who visited because of } \\
\text { alcohol use }\end{array}$ & 8823 & 15408 & $75.6^{\star}$ & 17167 & 27348 & $59.3^{\star}$ \\
\hline $\begin{array}{l}\text { No. of visits attributable to alcohol per } \\
\text { year in individuals with an initial visit, } \\
\text { mean }(95 \% \mathrm{Cl})\end{array}$ & $1.35(1.32-1.37)$ & $1.62(1.59-1.67)$ & $20.9 \dagger$ & $1.63(1.58-1.66)$ & $1.82(1.78-1.86)$ & $11.7 \dagger$ \\
\hline $\begin{array}{l}\text { Age-standardized rate of all-cause visits } \\
\text { (per } 10000 \text { population) }\end{array}$ & 3599.73 & 4312.52 & 19.8 & 3506.14 & 3806.97 & 8.6 \\
\hline $\begin{array}{l}\text { Age-standardized rate of visits } \\
\text { attributable to alcohol (per } 10000 \\
\text { population) }\end{array}$ & 20.71 & 38.62 & 86.5 & 51.12 & 78.31 & 53.2 \\
\hline Proportion of all visits attributable to alcohol & $0.59 \%$ & $0.88 \%$ & 49.1 & $1.49 \%$ & $2.04 \%$ & 36.9 \\
\hline
\end{tabular}

changes were greater among women, who had 1.63 times the increase in age-standardized incidence of emergency department visits attributable to alcohol compared with men. The percentage increase in the age-standardized rate of emergency department visits attributable to alcohol was 6.20 times greater in men and 4.37 times greater in women than the percentage increase in the age-standardized rate of all-cause emergency department visits. 
Age and sex patterns of emergency department visits attributable to alcohol use

Men and women showed bimodal distributions of emergency department visits attributable to alcohol use. The highest rates of emergency department visits attributable to alcohol were observed between ages 15 and 24 years in women and between ages 45 and 54 years in men. The largest increase in the rate of visits was in youths and young adults. Among individuals aged 25-29 years, the rate of visits attributable to alcohol increased by $240 \%$ (17.30 to 58.74 per 10000 individuals) in women and 145\% (37.48 to 91.72 per 10000 individuals) in men between 2003 and 2016. In addition, the age with the highest rate of emergency department visits attributable to alcohol increased in both women (from 15-18 yr in 2003 to 19-24 yr in 2016) and men (from $45-49$ yr in 2003 to $50-54$ yr in 2016) (Figure 1).

\section{Age-cohort effects in emergency department visits attributable to alcohol use}

We investigated the presence of age-cohort effects using a timetrend analysis examining changes in rates of emergency department visits at age 18,19 and 20 years for each subsequent birth year between 1986 and 1999. The average annual percentage increase in the rate of emergency department visits attributable to alcohol for women was $5.23 \%(95 \% \mathrm{Cl} 4.65 \%-5.82 \%)$ at 18 years, $5.83 \%(95 \% \mathrm{Cl} 5.28 \%-6.38 \%)$ at 19 years and $6.40 \%(95 \% \mathrm{Cl}$ $5.80 \%-7.00 \%)$ at 20 years, and for men was $2.30 \%(95 \% \mathrm{Cl} 1.88 \%-$ $2.93 \%)$ at 18 years, $2.65 \%(95 \% \mathrm{Cl} 2.17 \%-3.14 \%)$ at 19 years and $3.66 \%(95 \% \mathrm{Cl} 3.15 \%-4.17 \%)$ at 20 years. Supplementary Figures 1 and 2 (in Appendix 1) display a summary of these trends. Starting in 2007, female youth below the legal drinking age (aged 10-18 yr) had a higher rate of emergency department visits attributable to alcohol than male youth (aged 10-18 yr) who were under the legal drinking age (Appendix 1, Supplementary Table 3).
Association between income and emergency department visits attributable to alcohol use

Over the 14 years of study, individuals living in neighbourhoods in the lowest income quintile had more than twice the rate of emergency department visits attributable to alcohol than individuals living in neighbourhoods in the highest income quintile. This disparity was greater in men (RR $2.78,95 \% \mathrm{Cl} 2.71-2.86)$ than in women (RR 1.98, 95\% Cl 1.93-2.02). We used a time-trend analysis to examine changes in the disparity between rates of emergency department visits attributable to alcohol. Between 2003 and 2016, the average annual increase in the rate ratio in the disparity between the lowest and highest income quintile was $0.66 \%(95 \% \mathrm{Cl}$ $0.44 \%-0.89 \%)$ in men and $0.62 \%$ in women $(95 \% \mathrm{Cl} 0.31 \%-0.92 \%)$. This trend is shown in Appendix 1, Supplementary Figure 3.

\section{Interpretation}

Between 2003 and 2016, the increase in the age- and sexstandardized rate of emergency department visits attributable to alcohol was more than 4 times greater than the increase in the rate of all-cause emergency department visits. Although men had more than twice the age-standardized rates of emergency department visits attributable to alcohol that women had throughout the study period, the gap between the sexes narrowed over time. We observed that men and women exhibited unique, age-related patterns of emergency department visits attributable to alcohol, whereby visits were the highest for middle-aged men but peaked in younger women. However, for both sexes, the largest relative increase in alcohol harms over time was found among individuals aged between 19 and 35 years. Finally, individuals living in low-income neighbourhoods had more than twice the rate of emergency department visits attributable to alcohol than people in high-income neighbourhoods. This disparity increased slightly over the study period.
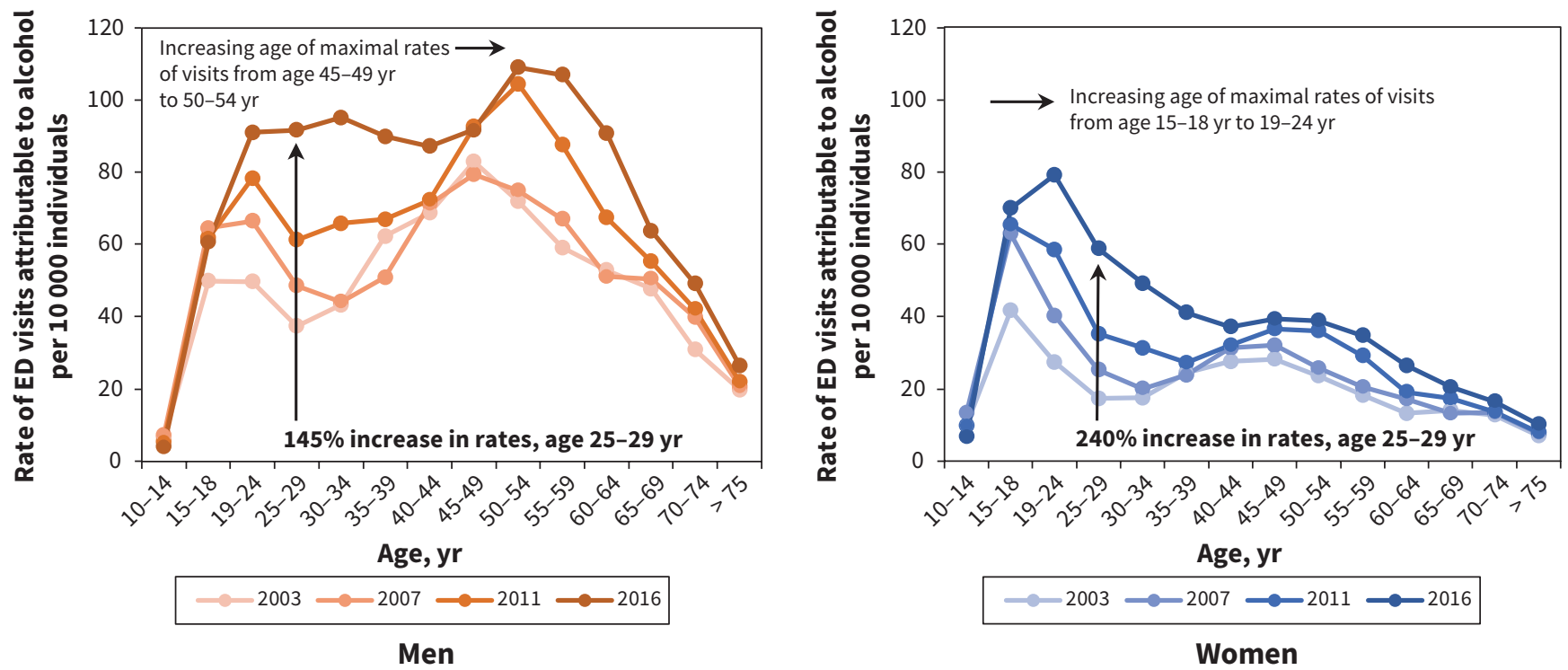

Figure 1: Cross-sectional trends (years 2003, 2007, 2011 and 2016) depicting the unadjusted rates of emergency department (ED) visits attributable to alcohol, in 5-year age increments for men and women. 
Our findings of the overall increase in harms attributable to alcohol are consistent with data showing increases in alcoholrelated emergency department visits in the US $(47.4 \%$ between 2006 and 2014), and alcohol-related hospital admissions in British Columbia (44.7\%) and England (50.8\%) between 2002 and 2014. ${ }^{3,4,11}$ Adding to the literature, our study identified important age, sex and income patterns in Ontario.

First, although men continue to have much higher rates of emergency department visits attributable to alcohol, rates of visits rose faster in women. These observed increases are consistent with data from Ontario and Canada indicating increasing average weekly alcohol consumption and rates of binge drinking over the study time frame, particularly among women. ${ }^{12,13}$ Second, youths and young adults in Ontario experienced the largest increase in emergency department visits attributable to alcohol. These observations signal a possible escalation in harmful patterns of alcohol consumption in younger Ontario residents with potential long-term implications for their health and patterns of health care use later in life. Third, we observed that the population-level increase in emergency department visits attributable to alcohol use is likely driven by the simultaneous rise in the number of individuals visiting the emergency department and by a higher number of repeated visits among these individuals. This finding suggests that there may be an increasing need for services targeting individual with high-risk alcohol consumption within our population. Fourth, consistent with the literature, we found income disparities in emergency department visits attributable to alcohol. ${ }^{7,14,15}$ However, unlike the increases in disparities (i.e., "deaths of despair") observed in the US, we found that this socioeconomic gradient has only modestly increased over time. ${ }^{6}$ Demographic differences, including less heavy drinking among lower-income groups in Canada than in the US, likely contribute to the discrepant trends. ${ }^{8}$ In addition, the alcohol-control environment in Ontario, which includes a minimum price on alcohol, likely reduced riskier patterns of alcohol consumption in lower-income groups. ${ }^{16}$ Importantly, although increases in alcohol harms have affected income segments of society equally, further interventions may be required to reduce the initial inequity.

This study was not designed to identify factors contributing to the observed increases in alcohol harms. However, 2 study features may help guide future research. First, our observations suggest that these factors are disproportionately affecting women and younger adults of both sexes. In fact, since 2007, the rates of emergency department visits attributable to alcohol among women have overtaken rates among men for individuals under the legal drinking age. Further research could examine youthspecific risk factors for alcohol harms in Ontario. Second, the alcohol-control environment in Ontario, which includes controls on alcohol price (indexed to inflation) and the availability of alcohol retailers, was stable until the final year of our study. ${ }^{17,18} \mathrm{We}$ can therefore infer that factors other than price and availability were likely driving the observed trends.

One possible contributor is increasing alcohol marketing and promotion, which is less tightly regulated in both Ontario and Canada. ${ }^{19}$ Recent studies of alcohol marketing in Canada are lacking; however, news reports and commentaries have high- lighted large increases in marketing directed specifically at women. ${ }^{20-22}$ Future work could explore whether Ontario is experiencing increased alcohol marketing and the potential contribution to the observed rising alcohol-related harms.

Although the alcohol-control environment was stable for most of the study period, it has recently undergone deregulatory changes, including an increase in the availability of alcohol sales (December 2015) and a reduction in the minimum price of alcohol (September 2018). ${ }^{18,23}$ Research, including evidence from Ontario and British Columbia, suggests that such policies may increase alcohol consumption and related harms. ${ }^{24,25,26}$ Further surveillance is needed of trends in alcohol-related harms in Ontario and Canada.

\section{Limitations}

Our study has several potential limitations. Our observed changes in emergency department visits attributable to alcohol could be partially explained by changes in diagnostic coding practices by physicians (i.e., the growing awareness of or decreased stigma for alcohol use disorders). However, the gradual increases across several diagnostic codes - including the codes for alcoholic liver disease, which has clear diagnostic criteria and is less likely to experience changes in coding practices - supports the validity of these findings as true increases in the number of events. In addition, the codes used in this study pertain to visits entirely attributable to alcohol, which are highly specific for alcohol-related harms. Although we expanded the literature by identifying population-level differences between demographic groups, our study design is susceptible to ecological fallacy and limited our ability to make causal inferences on individual-level risk factors associated with alcohol harms. Nevertheless, ecological studies are often important for hypothesis generation, and the findings presented here suggest there is a need to further investigate the association between individuallevel risk factors (e.g., age, sex, level of education and frequency of use) and the trends in alcohol harms, while accounting for potential within-subject correlation.

\section{Conclusion}

Consistent with global trends, health harms and the health system burden of alcohol have increased in Ontario. These harms have disproportionately affected women and young adults. Unlike trends observed in the US, we found only modest increases in the disparity in alcohol-related harm between socioeconomic strata. While further studies should focus on identifying the causes behind increases in these demographic groups, policymakers should consider increasing interventions to reduce harmful alcohol use, particularly in women and young adults.

\section{References}

1. GBD Compare. Seattle (WA): Institute for Health Metrics and Evaluation; 2018. Available: https://vizhub.healthdata.org/gbd-compare (accessed 2019 Mar. 17).

2. Alcohol harm in Canada: examining hospitalizations entirely caused by alcohol and strategies to reduce alcohol harm. Ottawa: Canadian Institute for Health Information; 2017. Available: www.cihi.ca/sites/default/files/document/ report-alcohol-hospitalizations-en-web.pdf (accessed 2017 Oct. 3). 
3. O'Donnell M, Sims S, Maclean MJ, et al. Trends in alcohol-related injury admissions in adolescents in Western Australia and England: population-based cohort study. BMJ Open 2017;7:e014913.

4. Green MA, Strong M, Conway L, et al. Trends in alcohol-related admissions to hospital by age, sex and socioeconomic deprivation in England, 2002/03 to 2013/14. BMC Public Health 2017;17:412.

5. Mullins PM, Mazer-Amirshahi M, Pines JM. Alcohol-related visits to US emergency departments, 2001-2011. Alcohol Alcohol 2017;52:119-25.

6. Case A, Deaton A. Mortality and morbidity in the 21st century. Brookings Pap Econ Act 2017;2017:397-476.

7. Tjepkema M, Wilkins R, Long A. Cause-specific mortality by income adequacy in Canada: a 16-year follow-up study. Heal reports 2013;24:14-22.

8. Probst C, Rehm J. Alcohol use, opioid overdose and socioeconomic status in Canada: A threat to life expectancy? CMAJ 2018;190:E1294-5.

9. NACRS emergency department visits and length of stay, 2015-2016. Ottawa: Canadian Institute for Health Information; 2017. Available: www.cihi.ca/en/ nacrs-emergency-department-visits-and-length-of-stay-2015-2016 (accessed 2018 Sept. 29).

10. Gorard S. Research design: creating robust approaches for the social sciences. London (UK): SAGE Publications; 2013. Available: http://methods.sagepub. com/book/research-design-creating-robust-approaches-for-the-social-sciences (accessed 2019 Apr. 16).

11. Alcohol and other drug (AOD) trend analyzer. Victoria (BC): University of Victoria; updated 2019 May 19. Available: http://aodtool.cfar.uvic.ca/aod (accessed 2018 July 26).

12. Ialomiteanu AR, Hamilton HA, Adlaf EM, et al. CAMH Monitor e-report: substance use, mental health and well-being among Ontario adults, 1977-2017. (CAMH Research Document Series No. 48). Toronto: The Centre for Addiction and Mental Health; 2018. Available: www.camh.ca/camh-monitor (accessed 2019 Apr. 15).

13. Cheng HG, Anthony JC. A new era for drinking? Epidemiological evidence on adolescent male-female differences in drinking incidence in the United States and Europe. Soc Psychiatry Psychiatr Epidemiol 2017;52:117-26.

14. Jones L, Bates G, McCoy E, et al. Relationship between alcohol-attributable disease and socioeconomic status, and the role of alcohol consumption in this relationship: a systematic review and meta-analysis. BMC Public Health 2015;15:400.
15. Probst C, Roerecke M, Behrendt S, et al. Socioeconomic differences in alcoholattributable mortality compared with all-cause mortality: a systematic review and meta-analysis. Int J Epidemiol 2014;43:1314-27.

16. Giesbrecht N, Stockwell T, Kendall P, et al. Alcohol in Canada: reducing the toll through focused interventions and public health policies. CMAJ 2011;183: 450-5.

17. O. Reg. 116/10: Minimum pricing of liquor and other pricing matters. Under the Liquor Control Act, R.S.O. 1990, c. L.18. Available: www.ontario.ca/laws/regulation /100116/v2 (accessed 2018 July 10).

18. Myran DT, Chen JT, Bearnot B, et al. Alcohol availability across neighborhoods in Ontario following alcohol sales deregulation, 2013-2017. Am J Public Health 2019;109:899-905.

19. Focus on: alcohol marketing. Toronto: Public Health Ontario; 2016. Available: www.publichealthontario.ca/en/eRepository/Focus_On_Alcohol_Marketing.pdf (accessed 2017 Nov. 13).

20. Female drinking on the rise as alcohol companies target women. CBC News 2013 Mar. 8. Available: www.cbc.ca/news/health/female-drinking-on-the-rise -as-alcohol-companies-target-women-1.1301479 (accessed 2018 July 23).

21. "Pinking" of alcohol marketing spurs culture of "wine moms," says author Ann Dowsett Johnston. CBC News 2018 Feb. 4. Available: www.cbc.ca/news/ canada/manitoba/ann-johnston-women-wine-moms-1.4517510 (accessed 2018 July 23).

22. Flegel K. Big alcohol catches up with adolescent girls. CMAJ 2013;185:859.

23. Newsroom: Premier Doug Ford announces return of "Buck-a-Beer" to Ontario [media release]. Toronto: Government of Ontario; 2018 Aug. 7. Available: https://news.ontario.ca/opo/en/2018/08/premier-doug-ford-announces-return -of-buck-a-beer-to-ontario.html (accessed 2018 Nov. 16).

24. Myran DT, Chen JT, Giesbrecht N, et al. The association between alcohol access and alcohol-attributable emergency department visits in Ontario, Canada. Addiction 2019;114:1183-91.

25. Stockwell T, Zhao J, Martin G, et al. Minimum alcohol prices and outlet densities in British Columbia, Canada: estimated impacts on alcohol-attributable hospital admissions. Am J Public Health 2013;103:2014-20.

26. Gmel G, Holmes J, Studer J. Are alcohol outlet densities strongly associated with alcohol-related outcomes? A critical review of recent evidence. Drug Alcohol Rev 2016;35:40-54.

\section{Competing interests: None declared.}

This article has been peer reviewed.

Affiliations: School of Epidemiology and Public Health (Myran), Faculty of Medicine, University of Ottawa; Clinical Epidemiology Program (Hsu, Smith), The Ottawa Hospital, Ottawa Hospital Research Institute; ICES uOttawa (Smith); Bruyère Research Institute (Hsu, Tanuseputro); Department of Medicine (Tanuseputro), University of Ottawa, Ottawa, Ont.

Contributors: Daniel Myran conceived the study, and is the lead author, corresponding author and guarantor. Peter Tanuseputro, Amy Hsu and Glenys Smith contributed to the study design, data interpretation and manuscript revisions. All of the authors contributed to the data analysis. Daniel Myran searched the literature.
All of the authors contributed to drafting the manuscript. Daniel Myran had full access to all the data in the study and had final responsibility for the decision on content and publication submission. All of the authors gave final approval of the version to be published and agreed to be accountable for all aspects of the work.

Funding: This study was supported by the Bruyère Research Institute through the Big Data Research Program and by ICES, which is funded by an annual grant from the Ontario Ministry of Health and Long-Term Care (MOHLTC). The opinions, results and conclusions reported in this paper are those of the authors and are independent from the funding sources. No endorsement by Bruyère, ICES or the Ontario MOHLTC is intended or should be inferred. The funder of the study had no role in the study design; data collection, analysis, or interpretation; or writing of the report.

Data sharing: The data set from this study is held securely in coded form at ICES. While data sharing agreements prohibit ICES from making the data set publicly available, access may be granted to those who meet pre-specified criteria for confidential access, available at www.ices.on.ca/DAS. The full data set creation plan and underlying analytic code are available from the authors on request, understanding that the computer programs may rely on coding templates or macros that are unique to ICES and are therefore either inaccessible or may require modification.

Accepted: June 5, 2019

Correspondence to: Daniel Myran, dmyra088@uottawa.ca 